\title{
The Motive of the Incarnation in Christian Theology: Consequences for Modern Cosmology, Extraterrestrial Intelligence and an Hypothesis of Multiple Incarnations
}

\author{
Alexei V. Nesteruk
}

\begin{abstract}
This paper addresses the question of the possibility of multiple species-specific incarnations of God in the societies of extraterrestrial beings (if they exist) on exoplanets, proposed for the debate in a recent volume on Astrlotheology. It gives a scientific, philosophical and theological assessment of some of its claims and concludes by formulating the position of the author on multiple incarnations in the context of modern cosmology and Orthodox theology.
\end{abstract}

\section{Introduction}

This paper addresses the question of the possibility of multiple species-specific incarnations of God in the societies of extraterrestrial beings (if they exist) on exoplanets, proposed for the debate in the volume on Astrlotheology. ${ }^{1}$ The strategy will be to respond to some claims in this book and conclude the discussion by formulating my personal position on multiple incarnations as I see it through the eyes of a cosmologist and an Orthodox theologian.

The major premise for such a debate originates in recent advances in observational astrophysics of exoplanets leading to a hypothesis that the necessary physical conditions for existence of carbon-based life-forms on these planets (similar to those on Earth) could entail that the sufficient conditions for their actual emergence, and emergence of intelligence are fulfilled. In other words, there is an inference: if exoplanets exist, then there can exist extraterrestrial intelligent life. Despite the fact that this assumption implies a biological reductionism, assuming intelligence as an epiphenomenon of the biological, it is considered in scientific circles as a reasonable extrapolation. Philosophy, which considers the phenomenon of humanity in a wider perspective (relating the human condition to personhood, morality, rationality etc.), doubts that the phenomenon of the Earthly humanity can be wide-spread and mediocre in the universe. Theology supports such a philosophical caution by advocating the uniqueness of humanity as experiencing creaturehood, longing for immortality and attainment of the union with the creator. In both, philosophy and theology, the phenomenon of humanity is treated as distinctively unique with no justification within metaphysica generalis, that is as

\footnotetext{
${ }^{1}$ T. Peters (ed.), Astrotheology. Science and Theology Meet Extraterrestrial Life (Eugene, Oregon: Cascade Books, 2018).
} 
unexplainable "event". ${ }^{2}$ Theology strengthens this point by relating the phenomenon of humanity to God (Imago Dei), characterising it through the paradox of human subjectivity (being bodily in a particular location in the universe while being able to articulate the entire universe through consciousness), the paradox whose sense was explicated by Christ in the Incarnation. Correspondingly, if such a phenomenon of humanity is elevated to a mediocre status in the universe (in the hypothesis of extraterrestrial life), this kind of thinking is manifest of anthropomorphism in its strongest possible sense, transferring the human sense of existence from Earth to other locations in the universe. ${ }^{3}$ Only in this case the question about the moral predicaments of the supposed extraterrestrial beings, their religion and their salvation can be raised. Only in this case a theological question on whether the other beings need incarnation of the Word of God. Correspondingly, our assessment of existing views on multiple incarnations will be based on a premise that an epistemological anthropocentrism is present in the very formulation of the problem (in spite of an initial intention to overcome such an anthropocentrism).

Ted Peters in his paper "One incarnation or many?" lists four logical positions on the possibility of multiple incarnations of the Logos of God in different locations in the universe. ${ }^{4}$ All these positions assume unconditionally two things: 1) there are necessary physical conditions in the universe such that the phenomenon of humanity and hence the Incarnation on Earth is possible in principle; 2) there have been actualised the sufficient conditions for the appearance of humanity in the universe and actual event of the Incarnation on Earth. There is a fundamental distinction between necessary and sufficient conditions: the necessary conditions can be interpreted in terms of the natural aspects of the universe by using science, whereas the sufficient conditions escape physical causality and place both the phenomenon of humanity, as well as the historical Incarnation in rubrics of "events" which escape description in terms of the underlying ontology. This means that the issue of existence of extraterrestrial life-forms, as well as multiple incarnations has sense not so much in the context of physics of the universe (covered by the necessary conditions), but related to some trans-natural, theological factors. This is the reason why the four logical positions formulated by Peters on

\footnotetext{
${ }^{2}$ J.-L. Marion, Certitudes negatives (Paris: Bernard Grasset, 2010), pp. 8-50.

${ }^{3}$ This is the reason why Russels's claim, based on the postulate of the "universality of imago Dei" (following in his logic from the similarity of the physical and moral conditions), that God provides multiple incarnation wherever ETI has evolved (R. J. Russel, "Many Incarnations or One?" In T.Peters (ed.) Asthrotheology, pp. 303-305) seems to be philosophically unjustified.

${ }^{4}$ T. Peters, "One Incarnation or Many?", Astrotheology, p. 297.
} 
multiple incarnations are essentially reduced to the differences in theological views on the concreteness of the Incarnation and its link to the essence of humanity.

The first, theological, alternative, according to Peters, is the difference between the position of whether the actual historical Incarnation was caused by the Fall of man in order to heal it, or the Incarnation would happen anyway regardless human actions and thus is inherent in the logic of creation of the world by God. Interestingly enough in both of these positions the cause of the Incarnation is shifted towards either the event of the Fall, or the creation. All discussions related to the causation between the Fall and the historical Incarnation are thus related to an attempt to formulate the sufficient conditions of the Incarnation in terms of the Fall. An alternative to this is to say that the actualisation of the sufficient conditions of the Incarnation has nothing to do with the Fall and human concerns, thus being inherent in the motive of creation in parallel with the necessary physical conditions. In both cases the historical contingency of the event of the Incarnation is neutralised by referring to some other inaugural events which acquire a status of the ultimate ontological justification. If the world was initially created through physical laws in order to sustain human flesh in the state of the Fall, the real significance of the event of the Fall in the whole history of salvation becomes blurred, because the necessary conditions for existence of humanity in the state of the Fall (in "garments of skin") are pre-existing in the very creation of the world.

Then there is the second pair of logical positions, according to Peters, which brings into play human beings: if the Incarnation happened on this planet either because of the Fall or through the inherent logic of creation, the question is about its uniqueness. Whether its happening on Earth is unique and theologically sufficient for the whole universe (regardless alien life-forms) or, it can happen somewhere else. As we stated above, the assumption of intelligent subjects elsewhere in the universe represents an anthropomorphic extrapolation of humanity into space. The assumption of the Incarnation on other planets then represents the fortification of this anthropomorphic stance even further, by assigning to other intelligent beings either the predicaments of humanity in its earthly condition, or by endowing alien forms of life by the dignity of the Imago Dei. In either cases the major issue is on the sense of humanity in its link to the Incarnation and whether this sense can be transferred to other possible intelligent species in the universe. 
Peters himself takes, according to him, the most coherent position of a fix-a-brokencreation Christology relying on the single Earthly incarnation event. ${ }^{5}$ Robert Russel argues that God provides multiple incarnations wherever extraterrestrial intelligence has evolved. ${ }^{6}$ Peter Hess follows Russel by asserting that "the postulation of multiple incarnations overcomes the time and distance problems, allowing the one God fellowship with creatures whenever and wherever they live throughout the universe." ${ }^{7}$ Joshua Moritz takes a negative stance on multiple incarnations accentuating the central role of humanity in the universe as being "an elected image of God...chosen from among the myriad of life forms in the cosmos .... and given the tasks of obedience and commandments, peace-keeping dominion, and cosmos-healing atonement." ${ }^{\prime 8}$ My personal position radically differs from those ones of Russel and Hess, for I'll argue that the hypothesis (postulation) of the multiple incarnations is an extreme anthropomorphic extrapolation having only an hypothetical and heuristic sense with no ontological justification. As to Peter's position I argue, contrary to him, for the incarnation-anyway model with the exclusive role played by humanity in the Divine image similar to that which was advocated by Moritz, but inclining towards its fundamental theological-ontological exclusiveness related to unknowability of man by himself. It is this unknowability that entails the incomprehensibility of the Incarnation and hence a purely hypothetical quest for its multiple doubles in other worlds.

\section{Centrality of Humanity: One Incarnation Suffices for the Entire Cosmos}

The phenomenon of humanity and the vision of Jesus Christ as the incarnate Son of God make the Incarnation an empirical fact, the fact which predetermines the contingent facticity of the whole universe. For the Word-Logos of God to assume human flesh, there must be this flesh. Since modern physics and biology are clear with respect to the necessary conditions of existence of such a flesh requiring at least ten billion years of a cosmological evolution, it seems evident that for the Incarnation to take place the necessary physical conditions must have been fulfilled. To have a body of Christ and his Mother (Virgin Mary) the universe must have had from the beginning the propensity to produce them. Correspondingly the ontological

\footnotetext{
${ }^{5}$ Peters, "One Incarnation or Many?", p. 297, see also p. 272.

${ }^{6}$ Russel, "Many Incarnations or One?", p. 303.

${ }^{7}$ P. M. J. Hess, "Multiple Incarnation of the One Christ", Astrotheology, p. 327.

${ }^{8}$ J. M. Moritz, "One Imago Dei and the Incarnation of the Eschatological Adam", in Astrotheology, p. 344.
} 
aspect of the Incarnation ${ }^{9}$ is always present in the reversed history of the universe as it is described in modern cosmology. ${ }^{10}$ According to T. Torrance the whole surrounding world, being created freely in the act of Love between the Persons of the Holy Trinity the world, exhibits nevertheless contingent necessity related to its physical structure, its space and temporal span, encoding the motive of the Incarnation in the fabric of creation. ${ }^{11}$ Torrance related the whole spatial structure of the universe (which is responsible for the necessary conditions of existence for all constituents of the universe ${ }^{12}$ ) to the Incarnation. ${ }^{13}$ By uniting hypostatically his Divine nature with human nature, the Logos subjected the freedom of creation to its particular realisation in human flesh. The Incarnation, being an "event" in space and time defines the modus of existence of the universe being implicitly present in the motive of creation.

As an empirical fact the Incarnation is intimately linked to humanity as part of creation. Maximus the Confessor, for example, refers to man created in the image of God as a key to understanding creation in his process of divinization when he may elevate it to the supreme level of its full soteriological comprehension. Since the actual historical Incarnation happens in the midst of the human subset of the universe (recapitulating the universe on the level of consubstantiality and epistemological acquisition), its proper sense can be directly related to the constitution and meaning of the cosmos. ${ }^{14}$ In this case one can claim that by contributing to the constitution of the cosmos, the Incarnation predetermines the existence of other exoplanets and possible life-forms thus involving them into its own logic from the beginning of the world. Then one can infer that the necessary conditions for existence of alien

\footnotetext{
${ }^{9}$ The ontological view of the Incarnation can be seen through a modern theological development called "deep Incarnation" (N. Gregersen, "The Cross of Christ in and Evolutionary World", Dialog: A Journal of Theology, vol. 40, n. 3, 2001, pp. 192-207).

${ }^{10}$ These conditions are summarised in various versions of the Anthropic Principle (AP), which detects consubstantiality of the physical stuff of the universe and human corporeal beings. Seen in this angle a hypothesis of the alien corporeal intelligence represents the extension of the AP with respect to other life-forms. In this sense when one invokes an idea of alien life one does not overcome anthropocentrism (whereas one can claim that it overcomes geocentrism) on the substantial level, for the physical and biological stuff on other planets will be the same, consisting of the evolutionary products of the burning stars.

${ }^{11}$ T. Torrance, Divine and Contingent Order (Edinburgh: T\&T Clark, 1998).

${ }^{12}$ The dimension of space $\mathrm{d}=3$, for example, is responsible for the stability of atoms and hence all astrophysical objects.

${ }^{13}$ The Strong AP transform into a Theo-Anthropic Principle related not to the possibility of a biological organization of man, but to the possibility of the Incarnation.

${ }^{14}$ See e.g. L. Thunberg, Man and the Cosmos (Crestwood: St. Vladimir's Seminary Press. 1985), p. 76 referring to Maximus' Questions to Thalassius 35.
} 
forms of life in some other locations in the universe have in their deep foundation the logic of the Incarnation on Earth, not requiring any ad extra, related to the physico-biological functioning of these aliens. In this sense the existence of Earth and human beings represents that fact which suffice for a claim that the necessary conditions of the Incarnation are fulfilled in the entire cosmos.

At the same time the actual happening of the Incarnation provides us with the transcendent indications (paradeigmata) of the undisclosed sufficient conditions responsible for existence of intelligible life and hence the articulated image of the universe. The sufficient conditions for the Incarnation are not part of the underlying ontology of the world and here the revelational aspect of the Incarnation that enters the discussion framed in terms of the inauguration of the Kingdom of God. Then there is a question: do the contingent sufficient conditions for a single historical Incarnation on Earth entail the necessity of its salvific consequences in the whole universe? If humanity is unique, then the Incarnation is addressed to this humanity and, strictly speaking, has a very tangential meaning to the rest of the universe. In this case it is humanity that is responsible for the salvation of the entire cosmos. If, on the contrary, one assumes existence of different forms of intelligent life, what is not clear is their relation to the Earthly Incarnation. One does not mean the physical conditions of their existence, but the relevance of their existence to God of Christian Faith. Indeed, all species in the universe were created by the same divine Logos, but the Incarnation is not part of the natural conditions in the world. Even if the world was created in order to attain the union with God, it is humanity which is granted the means of such an attainment through a special call. The possibility of such an attainment effectively contributes to the definition of man: only in communion with God man becomes "himself." 15 In this sense man, in spite of being consubstantial to the visible creation and having solidarity with it, is a special creation whose essence requires grace, the mechanism of acquiring of which proceeds through the Incarnation. ${ }^{16}$ On this basis I doubt any evidence that the rational creatures would be by nature attuned to the presence of God. ${ }^{17}$ If this would be true, we should identify these creatures with humanity. But this seems to be weak not only scientifically, but first of all philosophically: we do not have any evidence whatsoever to expect to encounter another type

\footnotetext{
${ }^{15}$ J. Zizioulas, Communion and Otherness (London: T\&T Clark, 2006), p. 248.

${ }^{16}$ This goes contrary to that which Russel asserts that "God's grace will redeem and sanctify every species in which reason and moral conscience are kindled" (Russel, p. 305) unless the mentioned species is part of the humankind.

${ }^{17}$ Peters, p. 285
} 
of "humanity" in a different world, unless we produce this "humanity" ourselves in a manner of science fiction. If this would be the case, still it is the Earthly humanity would have responsibility for "off-world doubles."

In view of that which has been said it seems to us that the idea of multiple incarnations can only be exercised with respect to those extra-terrestrials which have the same "anthropology", that is if they represent a copy of humanity. In this case the Earthly Incarnation will be sufficient for redemption of the off-world siblings. In all other cases the very supposition that the incarnational narrative can be transferred to other locations and other species of living beings in the universe remains an unjustified hypothesis.

\section{The Orthodox Position: Single Anyway Incarnation (the Arch Creation-Deification versus the Arch Fall-Redemption)}

The formulation of the Orthodox position on multiple incarnations starts from a referral to the ancient question of why God became man (Curs Deus Homo?). The traditional link between the Fall and the Incarnation is that the latter is treated as a redeeming act of God towards saving the transgressing humanity. The discussion of "Cur Deus Homo?" has never been a part of the canonical corpus of Orthodox literature and constituted, in words of G. Florovsky, a theologumenon (theological opinion). However Florovsky pointed towards a connection between creation and the Incarnation, as being, de facto, a necessary and sufficient condition for the created to be brought to union with God. In other words, the motive of the Incarnation is linked to the aim of creation. According to Florovsky, "It seems that the 'hypothesis' of an Incarnation apart from the Fall is at least permissible in the system of Orthodox theology and fits as well enough in the mainstream of Patristic teaching. An adequate answer to the 'motive' of the Incarnation can be given only in the context of the general doctrine of Creation." ${ }^{18}$ On the other hand, according to Maximus the Confessor, the creation of the world contained the goal for which all things were created: "For it is for Christ, that is, for the Christic mystery, that all time and all that is in time has received in Christ its beginning and its end." ${ }^{\prime 19}$ It in this sense that the motives of creation and the Incarnation are inextricably intertwined.

\footnotetext{
${ }^{18}$ G. Florovsky, "Cur Deus Homo? The motive of the Incarnation", in Creation and Redemption, The collected works of Georges Florovsky, vol. III, (Belmont, Mass.: Nordland Publishing Company, 1976), p. 170 (Emphasis added).

${ }^{19}$ Maximus the Confessor, Questions to Thalassius, 60.
} 
In accordance with this and, as we articulated above, the structure of the created world intrinsically contains the conditions for the possibility of the Incarnation. However, there remains a basic question on whether the actual happening of the Incarnation depends on human actions and the Incarnation becomes a measure to rectify the human fault. By linking the motive of the Incarnation to the intrinsic logic of creation of the world by God, Orthodox theology extends the scope of the Incarnation beyond the opposition Fall-Redemption, towards a more wider span of the plan of salvation as related to the deification of man and bringing the whole creation to the union with God. The lesser arch of the Fall-Redemption becomes a tool in restoring the greater arch Creation-Deification. ${ }^{20}$ In this sense the conditioning of the Incarnation by the human concerns would be a mistake: "Christ is not a mere event or happening in history. The incarnation of the divine Logos was not a simple consequence of the victory of the devil over man...The union of the divine and the human natures took place because it fulfilled the eternal will of God"21 so that it "...showed us that this was why we were created, and that this was God's good purpose concerning us from before ages, a purpose which was realised through the introduction of another, newer mode," 22 that is the entrance of "the incorporeal and incorruptible and immaterial Word of God [into] our world." ${ }^{, 23}$ A famous phrase from Athanasius that God "assumed humanity that we might be made God" 24 implies that humanity, being created, has a potential to be in union with God (not based in the natural laws related to creation). One can say stronger that a creaturely modus of existence becomes unavoidable for the very possibility of deification. The integrity of the human commitment to its transfiguration was expressed by Maximus the Confessor advocating the mediating role of man in overcoming the moral tensions between different parts of creation ${ }^{25}$, including, one can suggest, extraterrestrials. Man is the "microcosm" who resumes, condenses, recapitulates in himself the degrees of the created

\footnotetext{
${ }^{20}$ A. Louth, "The place of Theosis in Orthodox theology", in Partakes of the Divine Nature: The History and Development of Deification in the Christian Traditions, M. J. Christensen and J. A. Wittung (Madison: Fairleigh Dickinson University Press), p. 34-35.

${ }^{21}$ P. Nellas, Deification in Christ. Orthodox Perspectives on the Nature of the Human Person (Crestwood: St. Vladimir's Seminary Press, 1997), p. 37 (emphasis added).

${ }^{22}$ Maximus the Confessor, Ambigua, PG 91: 1097C [ET: On Difficulties in the Church Fathers. The Ambigua. Vol. 1., Ed. and tr. N. Constas, Cambridge, Mass.: Harvard University Press, 2014, p. 131133]

${ }^{23}$ Athanasius, On the Incarnation, 8 [ET: Crestwood, NY: St Vladimir's Seminary Press 1996, p. 33].

${ }^{24}$ Athanasius, On the Incarnation 54 [ET: p. 93].

${ }^{25}$ See, for example, L. Thunberg, Microcosm and Mediator: The Theological Anthropology

of Maximus the Confessor (Chicago: Open Court, 1995), pp. 387-427.
} 
being and because of this he can know the universe from within." 26 Correspondingly, if God's plan "consists in deification of the created world" (some parts of which imply salvation), the plausibility of the plan of deification is rooted in the fact that man is ontologically united with the created nature. Correspondingly man's created propensities placed in the framework of his Divine image would be sufficient to transfer the aim of creation, revealed through the Incarnation, to other alien beings. In this sense Orthodox theology links the Incarnation to humanity as that subset of the created universe which is capable of conducting a mediating role between different parts of creation, creation and God, where creation includes all alien forms of intelligence.

The cosmic sense of the Incarnation is articulated by Maximus the Confessor differently as such an event that brought a landmark in the temporal evolution of the universe, namely the division of its temporal span onto two fundamentally different aeons: "... according to this plan, it is clear that God wisely divided 'the ages' between those intended for God to become human, and those intended for humanity to become divine." 27 This sheds the light on the inclusion of the lesser arch of Fall-Redemption into the greater one of Creation-Deification as the different degrees of participation in God. This excludes a possibility of treating the movement from creation to deification through the Incarnation as a "natural process" inherent in the fabric of creation. On the one hand created things participate in God through the fact of their existence, that is through "being in communion." However, when Maximus enquires in the human capacity of deification, he stresses that it does not belong to man's natural capacity: “...what takes place would no longer be marvellous if divinization occurred simply in accordance with the receptive capacity of nature." 28 Maximus is concerned with the reciprocity between God and man. However the "reciprocity" has a passive character until the movement of God towards man fulfils in the Incarnation. The reciprocity by creation in the perspective of the Incarnation, however, does not achieve the likeness of man to God. This is the reason why Maximus claims that the aeon after the Incarnation corresponds to a contrary movement of man to God, whose very possibility was effected by the Incarnation. By separating the aeons before and after the Incarnation Maximus makes a difference between the participation in God which is bestowed

\footnotetext{
${ }^{26}$ O. Clément, "Le sense de la terre" Le Christ terre des vivants. Essais théologiques. spiritualite orientale, n. 17, (Bégrolles-en-Mauges: Abbaye de Bellfontaine, 1976) p. 90. ${ }^{27}$ Ibid.

${ }^{28}$ Maximus the Confessor, Ambigua 20 [ET: Nicholas Constas, On the Difficulties in the Church Fathers, The Ambigua, vol. 1 (London \& Massachusetts: Harvard University Press, 2104), p. 411].
} 
to man by creation and that participation which is bestowed by deification. The latter requires grace which is not implanted in the natural conditions of existence, but which is bestowed by God on the grounds of man's personal extent of perfection. ${ }^{29}$ This grace can be acquired by man and used for the transfiguration of the universe, including the alien species.

However, in view of the fact that life and intelligence emerged recently in history of the universe, the claim of the central role of humanity for the deification of the universe, including possible alien life-forms, demands a comment. Indeed, the phenomenon of humanity is a very short fragment of the universal history. The main question that remains is not about the participation of possible extra-terrestrial aliens in God bestowed by their being created but about their possible participation in deification before and after the event of the Incarnation on Earth. As we have discussed above, this event predetermines not only the representation of the universe by humanity, not only it anticipates the future Kingdom, but, de facto, defines the whole span of creation from the past to the future. ${ }^{30}$ Here is an inherent eschatological dynamics ${ }^{31}$ which drives material creation, including possible aliens forms of life, to perfection in God. By paraphrasing Peters, the Incarnation is an abbreviated cipher for the entire human life and death, the promise for the resurrection and renewal of all that exists in the creation. ${ }^{32}$ If the Incarnation was thought by God before the ages, its transcendent efficacy as of the event happened two thousand years in Palestine, being, by (as a motive of creation) commensurable with the whole span of the universe, has the sense of the inaugural event granting the universe its past and its (transfigured) future, exceeding the measure of the quality and quantity, beyond modality and relation, the manifestation of the impossible in that which has become possible.

\footnotetext{
${ }^{29}$ L. Thunberg, with reference to Maximus, asserts: "There is in man no natural power that can deify him, but there exists on the other hand a reciprocal relationship between God and man that permits him to become deified to the degree in which the effects of the Incarnation are conferred on him" (Thunberg, Man and the Cosmos, p. 55).

${ }^{30}$ Marcus Plested in his paper on pneumatology and new creation in Macarius of Egypt recapitulates the latter in following words: "But need realities such as the Fall be considered solely in linear terms? Might we not think of the Fall rather like a crack in the ice, spreading in all directions (and dimensions) from its center?...Might not the very fabric of creation be patterned on and adapted to the drama of Fall and Redemption in a non-linear and non-historical fashion?" (M. Plested, Pneumatology and the New Creation in the Macarian Writings: An Ecumenical Legacy", in M. Welker (ed.), The Spirit in Creation and new Creation (Grand Rapids: W. B. Eerdmans, 2012), p. 169-170.

${ }^{31}$ T. Peters, M. Hewlett, Evolution from Creation to New Creation (Nashville: Abingdon Press, 2003), p. 163.

${ }^{32}$ C.f. Peters, p. 300.
} 


\section{Conclusion}

In view of Ted Peters' classification of four logical positions with respect to the hypothesis of multiple incarnations, our position corresponds to anyway-incarnation model that relies upon a single Incarnation on Earth. Here is the recapitulation of my main points which rule out other logical positions.

1. The actual existence of humanity on Earth and the historical event of assumption of human flesh by God provides one with the evidence that the necessary physical conditions for the possibility of the Incarnation are fulfilled in the universe (anthropic principle, specific structure of space (Torrance), deep incarnation (Gregersen)) so that multiple incarnations (if they imply a similar mechanism) cannot be excluded on physical grounds. The issue becomes strictly theological and philosophical.

2. The historical incarnation of Christ is theologically treated as a contingently-necessary outcome of the arch of Creation-Deification, that is that motive of creation which can potentially lead (through man) to the attainment of the union with God. The role of humanity is not to condition the facticity the Incarnation through the Fall, but to use it as an archetype of acquiring grace making possible man's deification, renewal of creation and its transfiguration. Thus the Incarnation on Earth inaugurating the Kingdom of God suffices for transfiguration of all creation including alien forms of intelligence. On the grounds of this we consider a fix-a-broken-creation Christology as an incomplete constituent of the greater arch Creation-Deification.

3. Since the essence of humanity relies not only on a physico-biological structure but on the archetype of the Incarnate Son of God, the Incarnation can be treated as the constitutive principle of the human hypostatic intelligence on Earth, providing humanity with the mechanism of attainment of communion with God-creator. The latter is not implanted in the natural conditions of humanity and requires grace through an exercise of a particular type of transcendence pertaining to humanity as a special creation in the image of God. Hence there is no logical necessity for the Incarnation of the Son of God on other planets unless one makes an unjustified extrapolation of the human condition to other life-forms in the universe. Any speculation on the multiple incarnations seems to be an exercise of a strong "incarnational anthropocentrism" which is admissible epistemologically, but not ontologically. 
4. The Incarnation of the Son of God on Earth cannot be considered in isolation from the totality of the Christ-event that includes Resurrection, Ascension and the entrance of the Holy Spirit in the channels of history (Pentecost) within the arch creation-deification. Since this event happened on Earth, the latter is considered as soteriologically central in the universe. Earth's cosmographic mediocrity (implied by the discovery of exoplanets) does not influence its theological centrality. Indeed, according to Torrance, the universe is uniformly theogenic (God is present everywhere) thus effectively making the location of the Incarnation theologically equivalent to all possible locations in the universe. Thus the fundamental alteration in the order of nature effected in the Resurrection of Christ on Earth (impossible without the Incarnation), being an initial step in transfiguration of the universe, is efficacious for the whole creation. 